\title{
An Economic health Study for Treatment on Covid-19 Disease
}

\author{
Arshia Badi ${ }^{1}$, Farhad Rahbar, Esmail Nazem, Habibolah Arasteh Rad
}

Department of Complex Dynamics Modeling, Institute of applied Intelligent Systems, University of Tehran, Islamic Republic of Iran, Tehran

\begin{abstract}
Background, In this paper, drug treatment and vaccination are compared healthy and economically. In this comparison, in addition to comparing economic costs, it has paid attention to patients' recovery. To reach the goal, the prevalence of Covid-19 virus in New York is modeled by using the SEIR dynamic model. The SEIR dynamic model is used to model the period of epidemic diseases. Then, three disease control scenarios are evaluated economically. Treatment and vaccination are two important issues in controlling epidemic diseases. To control the disease, each of these two methods has economic costs and benefits. The main purpose of this paper is to compare the two methods of vaccination and treatment economically. Although the results of the study show that vaccination can be effective in preventing the epidemic of the disease than treatment, but due to the high cost and genetic mutation of the virus, vaccination is not the optimal method for both health and the economy in the long term.
\end{abstract}

Objective: Evaluation of treatment-based and vaccination-based methods in terms of economics and health to deal with the Covid-19 virus by using engineering methods to model the prevalence of coronavirus.

Method: The SEIR dynamic model was used to simulate the prevalence of the virus and the data on the prevalence of the virus in Wuhan, China, and New York State were used for simulation.

Results: A clear picture of macroeconomic and health decisions can be made in the field of infectious diseases using predictive methods in engineering and dynamic systems.

Conclusion: The results show that drug treatment is more economical than vaccination for coronavirus(2019-nCoV) epidemic diseases. In the study state and long term, treatment and vaccination for community health and the number of victims will not be much different. The corona-virus(2019-nCoV) has a clinical effect on $63 \%$ of those with the background disease, and many in the community do not need to be vaccinated. However, it is also important for people to consider health issues.

Keywords: SEIR Dynamic Model, 2019-nCoV, Treatment, Vaccination, Economical

\section{Introduction}

The end of 2019 and the beginning of 2020, the world was witnessing the epidemic of a new and emerging virus. The World Health Organization has named the virus Covid-19 [1]. Given the widespread prevalence of this disease, which has a high rate of epidemic, how to control and deal with important issues that have a significant impact on the lifestyle of human societies. In this article, we will discuss some of the ways to fight the disease with an economic perspective. Modern medicine has made significant progress in diagnosing and treating the disease. It can be said that modern medicine is an "industry" and has a certain relationship with the field of technology and economics. Modern medicine offers procedures that are cost-effective. It mainly tries to expand its influence as much as possible by using novel technologies. An industry thinks about cost and benefit, and its structure is based on mass production.

\footnotetext{
${ }^{1}$ arshiabadi@chmail.ir
} 
Therefore, prescribing a single drug for different people can guarantee more benefits. If a specific drug is prescribed for each patient, it will not be possible to mass-produce the drugs, then the profits of the pharmaceutical industry will be reduced. In the costbenefit approach to medicine, drug sales are of particular importance, not improving people's lives. Pharmaceutical companies are now looking to make money from patients. Such a problem has not been raised in the past. There is also a monopoly on the production of some drugs. In this case, people have to use only the products of one or two specific companies. In this case, their price and quality will not be competitive. Some doctors call the current system a "disease system" (instead of a health system), stating that "if both doctors and patients are dissatisfied, then someone else should be happy." Those who have made this system permanent and spread all over the world [2].

A new epidemic is very lucrative because we are sure there will be a big market for a new drug soon. Every once in a while, we hear the name of a new disease that occurs in some parts of the world and then spreads to other parts of the world. Many of these diseases are caused by contaminated food or new lifestyles, but some can be caused by other complications. For example in the case of AIDS, there is a lot of evidence that this virus is profitable. Dr. Hunt Kantol says in title of "Now it's time to start talking about the AIDS virus," about the creation of the AIDS virus: " Two researchers, Dr. Garth Nicholson and his wife Nancy, found a microbial bacterium (a mycoplasma) in the blood of about half of the sick soldiers in the Gulf War. It was unbelievable that this infectious agent had a high rate of genetic sequences of the AIDS virus. This germ can never form naturally. On the contrary, the microbial formula shows that it is a man-made factor in biological warfare and that its genetics have been manipulated. The same findings apply to Sars, Ebola, and the like. Professor Broderick, a professor at the University of Liberia and Delaware, believes that Ebola was a man-made disease in the genetic laboratories of Western pharmaceutical companies that was spread through UN vaccination programs in Africa. He published his article in the Liberian Daily Observer. He said the goal was to make it more profitable for pharmaceutical companies. In addition, the genocide of Africans to gain access to precious stone mines in the region has been another goal. She stressed that the US Army Medical Research Institute, the National Center for Disease Control in the United States and several other centers, including the World Health Organization, were involved in the project [3]. Although the illusion of conspiracy or blackmailing all global organizations is not the right thing to do, but man-made disease is very important. [2].

\section{- Coronavirus}

Coronaviruses are a large family of viruses that can infect animals and humans. Many of the coronaviruses that have been identified so far cause a range of respiratory infections in humans. They range from colds to more severe illnesses such as Middle East Respiratory Syndrome (MERS) and Acute Respiratory Syndrome (SARS). The newly discovered coronavirus is the causative agent of covid-19. [4] 


\section{- Covid-19}

The recently discovered coronavirus causes an infectious disease called Covid-19. The virus is a new disease that was unknown until December 2019. The virus first spread to the Chinese city of Wuhan. Fever, fatigue, and dry cough are the most common symptoms of Covid-19 disease. Some patients may have other symptoms such as pain and bruising, nasal congestion, runny nose, sore throat or diarrhea. These symptoms are usually mild and begin to gradually subside. Some people may not experience any of the symptoms of the disease and may not feel unwell. Most sufferers (about $80 \%$ ) recover without the need for specific treatment, and about one in six people with Covid-19 develop severe illness and shortness of breath. Elderly people who have underlying conditions such as high blood pressure, heart disease or diabetes are more likely to get worse. [4]

\section{- Review history}

As with other viral illnesses, it is possible to treat Covid-19 with medication and vaccines. It should be noted that each of these two methods has advantages and disadvantages. For example, the time it takes to make a vaccine is so long that it is practically available after many human casualties. On the other hand, the virus mutates in a short time and the vaccine made for the new virus will not work [5]. Also the cost of vaccine production is very high, while some studies have emphasized the ineffectiveness of the vaccine in the diseases [6,7,8]. Another disadvantage of vaccination is the large volume of hospital services to cover all members of society $[9,10,11]$. As mentioned, due to the high number of uses of a drug, many pharmaceutical companies are interested in producing vaccines. It is clear that selling a large volume of medicine will bring high profits to companies. Doctors' studies in China show that the new coronavirus virus occurs differently among new sufferers in the two northeastern provinces of the country compared to the first wave of the virus outbreak in Wuhan. Therefore, any changes or mutations in the new Corona virus could make it harder to develop a vaccine [5].

In 2020, Anderson et al. conducted a study entitled "The Impact of Influenza Vaccination in the Elderly, Hospitalization and Mortality." This study was used in a discontinuous regression design to alter the rate of vaccination at age 65 (due to agerelated vaccination policy in the UK). [12] In this paper, the comparisons were limited to people close to the age of 65 , and therefore most likely to be similar in most respects except for vaccination rates. Observational studies using traditional research have shown that influenza vaccination reduces hospitalization and mortality in the elderly. Accordingly, health authorities in some countries prioritize vaccination of this population. However, there are ambiguities about the effectiveness of vaccination. On the other hand, the similarity of the behavior of the Covid-19 virus with the influenza virus should be considered. The data in this paper included data collected from 170 million patients under care and 7.6 million patients who died. The statistical difference between seasonal influenza vaccination was statistically and clinically significant. However, no evidence suggests that vaccination reduces hospitalization or mortality in the elderly. Estimates were accurate enough to refute the results of many 
previous studies. This paper shows that given current vaccination guidelines, prioritizing older people suggests that complementary strategies may be needed. [12]

In a study titled "The Great Theory of Pharma", Robert Blascoitz et al. In 2017 examined diseases caused by humans. In this study, one of the most interesting allegations of human-caused diseases during the outbreak of H1N1 swine flu in 2009 was raised [13]. Mike Adams, a medical activist who advocates almost any conspiracy theory, made the accusation in 2009 in a bizarre little song called 'Don't Inject $\mathrm{Me}^{\prime}$.The big pharmaceutical companies are doing almost anything, just to make money with the flu vaccine. Adams makes two claims: one is that all you need to treat swine flu is vitamin D (but pharmaceutical companies can't afford it), and the other is that the flu was made to sell a vaccine. He also cites a global deprivation conspiracy as a market for vaccines; Two categories that do not match; One is killing people and the other is saving the lives of many people by vaccination. This is a hallmark of conspiratorial thinking. In 2012, a study by Douglas and Sutton found that conflicting conspiracy theories were positively related (in both cases, powerful individuals hid them) [14].

The great theory of drug conspiracy has common features with other conspiracy theories. The first is that it has the same basic plan: a few people secretly conspire against the public interest. Second, most Persons are unaware of the truth and only a few know the real purpose. (These Persons have confidential information and are under pressure because of this information; in fact, people who come up with conspiracy theories). Third, those who propose conspiracy theories have an inverted approach to evidence: Lack of evidence for conspiracy is itself evidence of conspiracy (or proves conspiracy) as any denial of such evidence. Finally, the way of dealing with affirmative evidence uses common mental shortcuts, misconceptions, and irrational cues that make all conspiracy theories more memorable, convincing, and transferable. This misleading combination of mistakes makes it very difficult to deal with conspiracy theories [13].

However, the types of big drug conspiracy theories are a special subgroup in the larger group of conspiracy theories. In fact, the main hypothesis of the great drug conspiracy theory is the "cui bono" sophistry: the one who enjoys misery must be the cause of this misery ...George W. Bush and his aides wanted to go to war in the Middle East, so they destroyed the World Trade Center under the pretext of invading Iraq. [13]

Malaria, tuberculosis and the HIV virus kill about five million people a year in Africa. However, there is very little research on the vaccine for these diseases, and the main reason is that vaccine manufacturers fear that they will not be able to sell the vaccines adequately and at a reasonable price to recoup the cost of re-searching. Mostly because of the potential vaccine developers, they are afraid that they will not be able to sell enough vaccines at a reasonable price to cover their re-search costs. Strengthening the new vaccine market can motivate you to seek out vaccines and increase access to any vaccines you develop. For example, the head of the World Bank has suggested that a fund be set up to help developing countries buy vaccines if 
they are invented. The US government's 2000 budget proposal includes a tax credit that can match each dollar of vaccine sales with one dollar of tax credit. Private companies are currently doing little research on vaccines against malaria, tuberculosis and the HIV virus in Africa. This is not only because these diseases primarily affect poor countries, but also because vaccines are subject to severe market damage due to non-carpeting. This is due to two reasons: first, that these diseases primarily affect poor countries, and second, that vaccines are vulnerable to corruption because they are not sold in the market. [15]

When vaccine developers invest in advanced vaccines, governments are tempted to use their powers as regulators, principal buyers, and intellectual property rights arbitrators to bring prices to a level where research costs Does not cover, deliver. Vaccine research is an international public good, and none of the many small countries that use malaria, tuberculosis, or HIV vaccine They have no incentive to encourage research by providing unilateralism to pay higher prices. In fact, most vaccines sold in different developed countries. At any dose, they are a small part of their social value. The more expensive vaccines are usually not bought by the poorest countries. Hence, private developers lack the motivation to pursue social value research opportunities. Large public purchases can potentially boost the vaccine market and benefit vaccine manufacturers as well as the general public. [15]

Vaccine production is not economically viable for low-prevalence and contagious diseases, as the vaccine industry is struggling with low-profit margins. "Many companies have focused their vaccine sector on profitable vaccines," says the Economist. In fact, the benefits of the low-prevalence vaccine have been so low that some companies have stopped making them. In 1967, 16 vaccines were produced, up from 17 in 1980 [16].

Infectious diseases of the vaccine are in high demand, so vaccines are very expensive. So that Doctors Without Borders recently called for lower vaccine prices for Pfizer and Glaxo Smith Kline for developing countries Regarding the reduction in vaccine prices, proponents of increasing vaccine prices, such as Bill Gates, responded that not only is vaccine production very complex, but the discovery of the vaccine requires significant research and development budgets [16].

One of the first mathematical models in epidemiology is the effect of vaccination. In 1760, Daniel Bernoulli, a Swiss mathematician, published a study on the effect of immunization with cow dung, based on life expectancy of the vaccinated population.

Nearly 150 years later, during World War I, Ronald Ross built a series of mathematical models of malaria outbreaks that laid the foundations for modern theory of infectious disease control. Ross discovered through mathematical modeling that mosquito control could prevent malaria transmission. [17]

Recognizing that the transmission of the disease is halted by control programs with incomplete coverage has had a profound effect on the design of intervention strategies. The simplest questions asked about vaccination strategies are: [17] 
(1) What part of the population must be successfully vaccinated to eradicate the infectious agent?

(2) What happens if the cover of the infectious agent is not eradicated?

(3) Will vaccine safety be reduced over time?

(4) What happens if there are vaccine-resistant subtypes?

Subsequent sections provide mathematical models that address these questions. In recent decades, mathematical models in epidemiology have been an important tool in the analysis and analysis of the spread and control of infectious diseases. The dynamic complexity of each disease dictates the use of simple mathematical models to gain insight into the spread of disease and testing control strategies [18].

Since the first application of optimal control in biomedical engineering was in the 1980s [19], Several vaccination strategies for infectious diseases have been successfully modeled as optimal control problems. The so-called computational models have been widely used in this field. One of these models is SEIR, which is based on dividing the study population into four sections. The person may be susceptible (S) to the disease but not yet infected (E), infected (I), or recovered (immune) (R). SEIR models can show many infectious human diseases such as measles, smallpox, influenza, dengue, etc. [20]

This article includes five main sections, the first part of which reviews the vaccination status, pharmaceutical industry and treatment methods along with the introduction of Covid-19 disease. In the second part, we will look at modeling in the United States as an example. In the third and fourth sections, using computer simulation, we implement the desired methods and review and compare them economically and healthily, and in the last section, the general results of this article will be shown.

\section{Modeling}

In this paper, we use data on the prevalence of coronary heart disease in the United States and New York State [21] and use the SEIR model to detect the prevalence of this disease and the effectiveness of each drug treatment and vaccination with respect to the economy and health as follows:

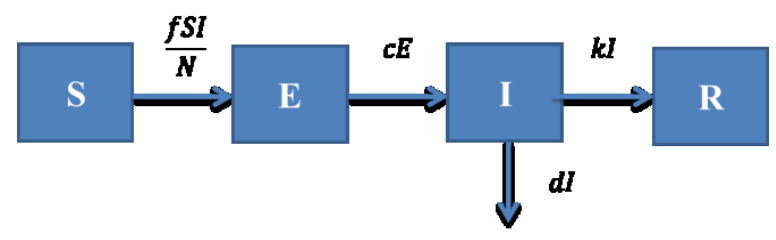

Figure (1): SEIR model based on reference [21]

The transmission model is based on the epidemiological aspects of the disease [21]. 
- In this study, the New York State population is divided into SEIR models, which consist of four parts: susceptible (S), exposed (E), infected (I), and recovered $(\mathrm{R})$. And the population is assumed to be unchanged. It is assumed that at first the whole population is susceptible, hence $S_{0}=N$.

- Due to the growing number of cases around the world in a short period of time, the disease is assumed to be contagious enough.

- Birth and natural death rates have not been seen in this model.

- It is assumed that 2019-nCoV is capable of transmitting between humans.

Differential equations (equations (1) - (4)), which describe the dynamics of 2019$\mathrm{nCoV}$ in the human population, are formulated based on a diagram first described in Figure (1). [21]

$\frac{d S}{d t}=-\frac{f S I}{N}$

$\frac{d E}{d t}=-\frac{f S I}{N}-c E$

$\frac{d I}{d t}=-c E-d I-k I$

$\frac{d R}{d t}=k I-u s$

In the above figure model, since zero of the patient may be infectious and moving and freely interact with susceptible humans, Therefore, susceptible humans are exposed to this disease at the rate of transmission (f). After exposure, the latent period begins, and after this period, These infections and contaminants are then transferred to the infected area at a rate of (c) and when they recover from the disease, they are transferred at an improved rate $(\mathrm{k})$. Also at the rate of $(\mathrm{u})$ The infected population is vaccinated. Once exposed, the incubation period begins, and after this period, these motions and groups that are exposed to contamination are transferred to the infected part at a rate of (c) and when they recover from the disease, at a rate of (k). ) Are transferred to the improved part. However, there are some contaminated items that may die due to disease with a certain rate (d)[21].Also, the infected population is vaccinated at the rate $(\mathrm{u})$.

\section{Model simulation}

To simulate, we use the 2017 Simulink software box of MATLAB software. The first confirmed case of Covid-19 infection was reported in New York State on March 1, 2020. [22] Therefore, the initial time of March 1, 2020 is considered a positive case. Table (1) shows the constant and initial parameters of SEIR model, respectively. It should be noted that the results of the simulations have been extensively reviewed and the results may be variable depending on the knowledge and behavior of the community regarding the virus. 
Table (1): SEIR model parameters

\begin{tabular}{|c|c|c|c|}
\hline \multicolumn{1}{c}{ Parameter } & Description & \multicolumn{1}{c}{ Value } & \multicolumn{1}{c|}{ Source } \\
\hline$N$ & Total human population & 8500000 & [23] \\
\hline$\frac{1}{c}$ & Incubation Period & $6.5($ Variable) & [24]( Variable) \\
\hline$f$ & \multicolumn{1}{c}{ Transmission rate of I to S } & 1.35 & estimate \\
\hline$\frac{1}{k}$ & Infectious Period & \multirow{2}{*}{$3.6($ Variable) } & [25]( Variable) \\
\hline$d$ & Death rate of 2019-nCoV & 0.001 & estimate \\
\hline$E_{0}$ & Exposed & 0 & {$[21]$} \\
\hline$I_{0}$ & Infected & 1 & {$[21]$} \\
\hline$R_{0}$ & Recovered & Variable & Variable \\
\hline$u$ & Vaccination & &
\end{tabular}

After performing the simulation for 300 days, we see that in Figure (3, right) the prevalence of Covid-19, as shown in the reference, is estimated to be more than 400,000 in the 10 to 135 days period (Figure 2 and 3).

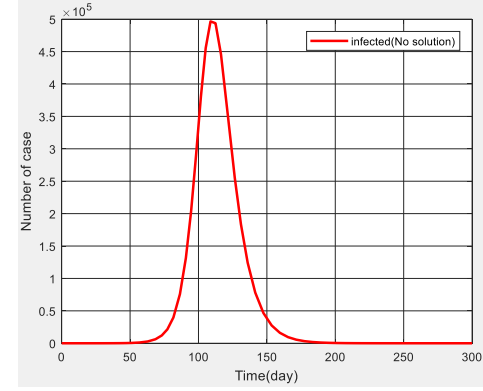

(a)

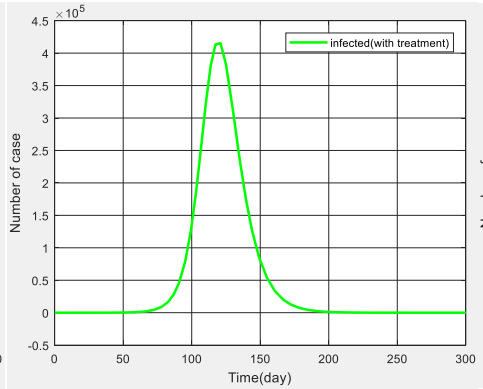

(b)

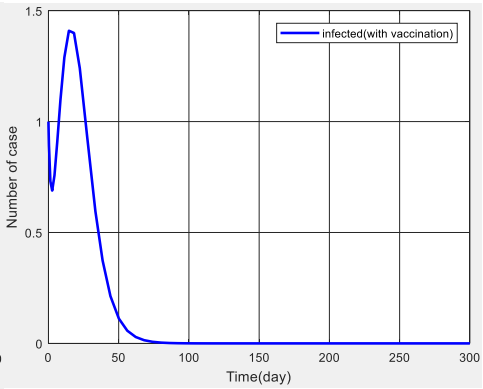

(c)

Figure (2): a: Disease-free rate of vaccination and vaccination only with prevention, $b$ :

Disease rate with drug treatment, c: Vaccination rate in ideal conditions

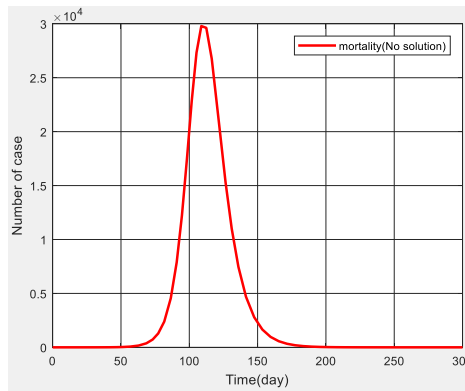

(a)

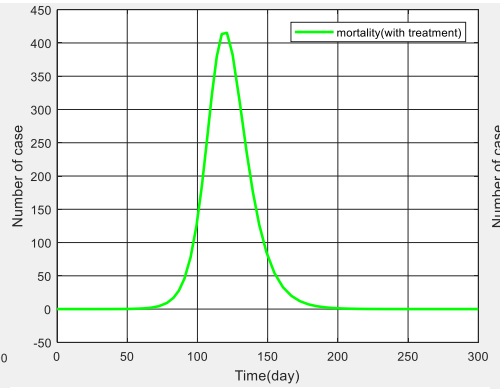

(b)

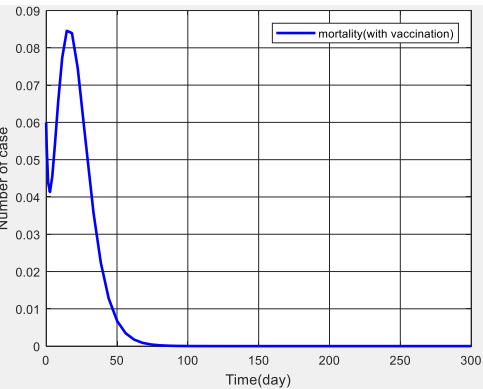

(c)

Figure (3): a: Mortality rate of the disease without drugs and vaccination only with prevention, b: Mortality rate of the disease along with the existence of drug treatment, c: Mortality rate with vaccination in ideal conditions 


\section{Economic evaluation}

In this section, we will model and calculate the cost of vaccination and drug treatment. It should be noted that the period of re-vaccination varies depending on the type of access. The cost of the vaccine in this article is considered a one-year period without renewal, and the mortality rate and human error resulting from the vaccine test on humans have not been modeled and are ideally ideal. (Treatment in case of injection) it has been shown.

\section{Vaccination scenario}

Vaccination of people in countries in turn includes the cost of vaccination, it is a medical service and should be kept in mind that not all people can be vaccinated immediately and "quickly", which is a factor in the spread of the virus. Percentage of vaccination results, especially in the primary year.

Table (2): Calculate the total price in the vaccination method

\begin{tabular}{lccc}
\hline $\begin{array}{c}\text { number of } \\
\text { Person }\end{array}$ & $\begin{array}{c}\text { The cost of each } \\
\text { person for } \\
\text { vaccination* }\end{array}$ & The total cost & Number of deaths(Person) \\
\hline 8500000 & $30 \$ 255000000 \$$ & About 216 \\
*: The cost of the vaccine is calculated based on about $50 \%$ higher than the price of the flu vaccine in \\
the reference [26].
\end{tabular}

\section{Vaccine supply and demand scenario}

If vaccine Covid-19 is released, the cost of vaccination for 7 million people is estimated in the table below. It is noteworthy that the vaccine will not be available to all people and there will be high demand for the vaccine in the market. The dynamic relationship of price change based on supply and demand is considered in the form of equation (5) [27]:

$\frac{d P}{d t}=f(A-x)$

In Equation (5), $(\mathrm{P})$ specifies the cost price, $(f)$ cross-sectional price increase, $(\mathrm{A})$ determines the demand level and (x) determines the supply quantity. (Table 3 )

Table (3): Calculation of total price in supply and demand vaccination method

\begin{tabular}{cccc}
\hline $\begin{array}{c}\text { number of } \\
\text { Person }\end{array}$ & $\begin{array}{c}\text { The cost of each person } \\
\text { for vaccination }\end{array}$ & $\begin{array}{c}\text { Supply rate } \\
\text { (unit) }\end{array}$ & The total cost \\
\hline 8500000 & $30 \$$ & 7000000 & $\mathbf{4 5 0 0 0 0 0 0 0 \$}$ \\
\hline
\end{tabular}




\section{Treatment scenario}

In this scenario, the cost of drug treatment for a patient with $\$ 100$ is considered. In Table (4), you can see the price of this method.

Table (4): Calculate the total price in the drug treatment method

\begin{tabular}{|c|c|c|c|}
\hline $\begin{array}{c}\text { Number of } \\
\text { deaths(Person) }\end{array}$ & The total cost* & $\begin{array}{c}\text { The cost of drug } \\
\text { treatment }\end{array}$ & $\begin{array}{c}\text { Estimate the number of } \\
\text { infections(Person) }\end{array}$ \\
\hline About 412 & $41500000 \$$ & $100 \$$ & 415000 \\
\hline
\end{tabular}

In general, the economic assessment of drug and vaccine treatment can be considered as follows: Current data show that the time between the onset of symptoms and clinical recovery in people with mild disease is about 2 weeks, and in people with severe disease or The crisis will take 3 to 6 weeks to heal. Also, a study of countries around the world shows that the rate of epidemics can be reduced and controlled after a period of time (such as China). Since governments impose social restrictions, the results show that countries with economic challenges will face serious challenges. Table 2 shows that if the vaccine is mass-produced at a price of $\$ 30$ (the price required to get the flu vaccine) and if there is an advanced health system, the mortality rate will be significantly reduced. Find. Given the current situation, it will be very difficult to achieve this. Table 3 shows the relationship between supply and demand, with a $17 \%$ decrease in supply in the market. It should also be noted that due to the prevailing climate in the people and society, the majority of people will want access to these therapists. Table 4 shows the supply of the drug to treat the disease. In pharmacological treatment, people will need it when dealing with the disease, and given that the amount of people involved is predictable due to the behavior of the disease, and according to the experience going on, not all people will be affected at once. It is possible to get the volume of drug production due to its low production scale, which is much more accessible and has effective control capability. The data in Table 4 show that the overall cost of vaccination is less than $10 \%$ of the cost of vaccination, according to estimates.

\section{Conclusion}

The Covid-19 virus has now become a global epidemic. Numerous scientific methods have been proposed to reduce the incidence and stop the spread. In this paper, the effectiveness of treatment and vaccination methods for controlling epidemics of Covid-19 virus were compared healthy and economically. In this comparison, in addition to comparing economic costs, it has paid attention to patients' recovery. To achieve this goal, the prevalence of the disease was modeled using the SEIR model. New York State data related to disease epidemics were used for simulation.

The simulation of the above model shows that while the treatment method costs only $\$ 41.5$ million, the vaccination method will cost more than $\$ 250$ million, which will increase to $\$ 455$ million if the vaccine is not available sufficiently. Since there is no 
guarantee that you will not be infected with the vaccine, and given that not everyone in the community can be vaccinated immediately, the mortality rate for the vaccination method has been calculated. Comparison of the two methods shows that the mortality rate in the vaccine is at best $40 \%$ lower than in treatment. The model shows that the incidence rate is about $5 \%$ during 135 days. About $3 \%$ of patients die. So vaccination can only have 200 deaths less than drug treatment in a population of 400,000. It should be noted that Covid-19 disease affects the heart and lungs. If the drug is found to be effective in respiratory disease, these drugs can also be prescribed for the mutated virus, but the vaccine will not be available for the mutated virus. And the cost of producing a new virus vaccine will be the same as the old virus vaccine.

Therefore, it can be concluded that the vaccination method, in addition to the very high cost of controlling such diseases, does not have an advantage over the pharmacological method, but should focus more on the pharmacological treatment method. The economic losses caused by the closure of economic centers will be doubled by the costly method of vaccination.

Although the results of the study show that vaccination can be effective in preventing the epidemic of the disease than treatment, but due to the high cost and genetic mutation of the virus, vaccination is not the optimal method for both health and the economy in the long term.

Although two important methods of drug treatment and vaccination are considered important, but due to the problems of most countries in the current situation, which have suffered from the economic crisis due to the consequences of quarantine and social distancing, it is very practical to purchase vaccines if discovered It's hard. The purpose of this paper is to show the cost of the drug against vaccination. As can be seen from the results, the difference in the cost of drug treatment with a large difference is economical. However, it should be borne in mind that more than $63 \%$ of patients have been infected with the underlying disease, so vaccination treatment is very expensive.

\section{Reference}

[1] World Health Organization (https://www.who.int/emergencies/diseases/novelcoronavirus-2019)

[2] Medical Mafia; Fake diseases in the service of "Medical Industry", Mashreq News Agency, November 2015, mshrgh.ir/380408

[3] https://www.trueactivist.com/evidence-mounts-ebola-made-in-the-usa-by-big-pharmadept-of-defense/

[4] World Health Organization,https://www.who.int/ar/emergencies/diseases/novelcoronavirus-2019-farsi/advice-for-public-farsi/q-a-coronaviruses-farsi 
[5] A new wave of corona outbreaks in China indicates a possible change in virus performance, Euronews reports, May 2020, https://per.euronews.com/2020/05/20/chinesescientists-say-new-covid19-outbreak-possible-modification-of-coronavirus

[6] S.Cesaro ; M.Giacchino ; F.Fioredda ; A.Barone ; L.Battisti ; S.Bezzio ; S.Frenos ; S.De Santis ; S.Livadiotti; S.Marinello; A. G. Zanazzo; D.Caselli ,"Guidelines on vaccinations in paediatric haematology and oncology patients". Biomed Res. Int. 2014: 707691. doi:10.1155/2014/707691. PMC 4020520. PMID 24868544.(2014)

[7] National Center for Immunization and Respiratory Diseases, "General recommendations on immunization - recommendations of the Advisory Committee on Immunization Practices (ACIP)". MMWR. Recommendations and Reports / Centers for Disease Control. 60 (2): 164. PMID 21293327.(2011)

[8] R. M.Wolfe,"Update on adult immunizations". The Journal of the American Board of Family Medicine. 25 (4): 496-510. doi:10.3122/jabfm.2012.04.100274. PMID 22773718.(2012)

[9] M.Quadri-Sheriff, K.S. Hendrix, S. M,Downs, L. A, Sturm, G.D.Zimet, S.M.Finnell ,"The role of herd immunity in parents' decision to vaccinate children: a systematic review". Pediatrics. 130 (3): 522-30. doi:10.1542/peds.2012-0140. PMID 22926181. (2012).

[10] E.Dubé, C.Laberge, M.Guay, P.Bramadat, R.Roy, J.Bettinger, "Vaccine hesitancy: an overview". Human Vaccines \& Immunotherapeutics. 9 (8): 1763-73. doi:10.4161/hv.24657. PMC 3906279. PMID 23584253. (2013).

[11] D.Ropeik, "How society should respond to the risk of vaccine rejection". Human Vaccines \& Immunotherapeutics. 9 (8): 1815-18. doi:10.4161/hv.25250. PMC 3906287. PMID 23807359. (2013)

[12] ML.Anderson, C.Dobkin, D.Gorr. The Effect of Influenza Vaccination for the Elderly on Hospitalization and Mortality: An Observational Study With a Regression Discontinuity Design. Ann Intern Med. 2020;172(7):445-452. doi:10.7326/M19-3075

[13] R.Blaskiewicz,The Big Pharma conspiracy theory, The European Medical Writers Association, 2013 VOL. 22 NO. DOI:10.1179/2047480613Z.000000000142.

[14] Wood MJ, Douglas KM, Sutton RM. Dead and alive: beliefs in contradictory conspiracy theories. Soc Psychol Personality Sci 2012;3:767-73.

[15] M.Kremer ,Creating Markets for New Vaccines Part I: Rationale , Harvard University, The Brookings Institution, and NBER.

[16] Vaccines Are Profitable, So What?, BOURREE LAM, The Atlantic, FEBRUARY 10 , 2015,https://www.theatlantic.com/business/archive/2015/02/vaccines-are-profitable-sowhat $/ 385214 /$ ?utm source=share\&utm campaign=share

[17] A.Scherer, A.McLean, Mathematical models of vaccination, British Medical Bulletin, Volume 62, Issue 1, July 2002, Pages 187-199, https://doi.org/10.1093/bmb/62.1.187

[18] F. Brauer and C. Castillo-Chavez, Mathematical Models in Population Biology and Epidemiology, Springer-Verlag. New York, 2001.

[19] D. S. Naidu, T. Fernando and K. R. Fister (2011), Optimal control in diabetes, Optim. Control Appl. Meth., 32, 181-184. 
[20] M. H. A. Biswas, L. T. Paiva, MdR de Pinho(2014). A SEIR model for control of infectious diseases with constraints. Mathematical Biosciences and Engineering, 2014, 11(4): 761-784. doi: 10.3934/mbe.

[21] J.Labadin, B.H.Hong (2020),Transmission Dynamics of 2019-nCoV in Malaysia View , medRxiv ,doi: https://doi.org/10.1101/2020.02.07.20021188

[22] https://news.google.com/covid19/map?hl=fa\&mid=\%2Fm\%2F02 286

[23] The Star. (2020, Feb 4). First Malaysian tests positive for Wuhan coronavirus. Retrieved Feb 5, 2020, from https://www.thestar.com.my/news/nation/2020/02/04/first-malaysiantestspositive-for-wuhan-coronavirus 5. The Star. (2020, Feb 7). Coronavirus:

[24] DOSM. (2019, Nov 14).Demographic Statistics Third Quarter 2019, Malaysia. Retrieved 3 February 2020, from, https://www.dosm.gov.my/v1/index.php?r=column/cthemeByCat\&cat=430\&bul_id=YkdwY kZYOVQ5WFJ4dXhEelNpbGRmZz09\&menu_id=L0pheU43NWJwRWVSZklW'WdzQ4TlhU U T09.

[25] J. M.Read, J.R.Bridge, D.A. Cummings, A. Ho, C. P.Jewell, Novel coronavirus 2019nCoV: early estimation of epidemiological parameters and epidemic predictions. medRxiv.(2020)

[26] National Center for Immunization and Respiratory Diseases(2020), https://www.cdc.gov/vaccines/programs/vfc/awardees/vaccine-management/pricelist/index.html

[27] Y. Charles . H.Yang. A Mathematical Model of Demand-Supply Dynamics with Collectability and Saturation,International Journal of Bifurcation and Chaos ,27:01.(2017)

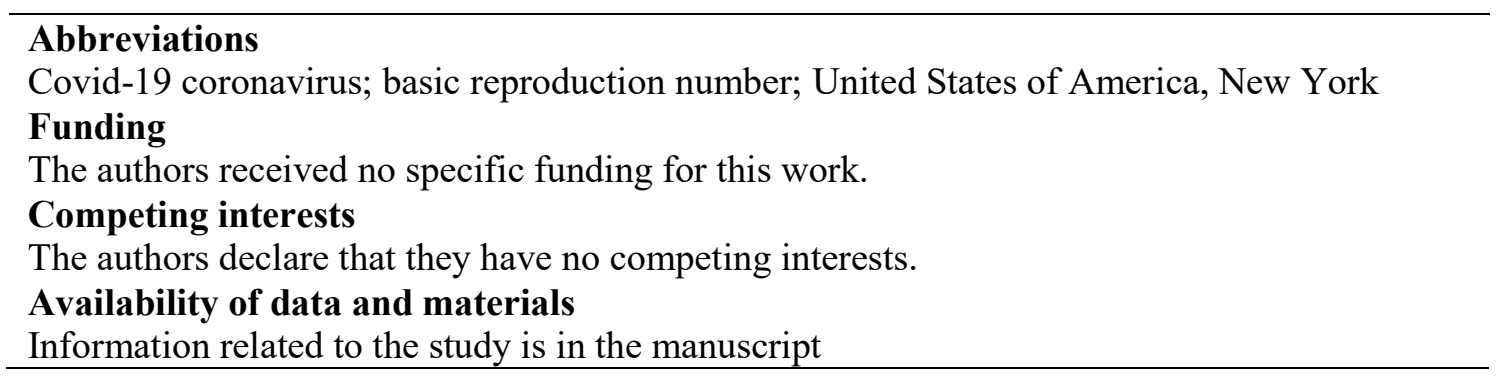

